\title{
Essay on Igbo Folk Medicine as an Indispensable Aspect of Health Care Delivery in the $21^{\mathrm{ST}}$ Century
}

\author{
Aloy Nnamdi Obika ${ }^{1}$, Obiora Eke ${ }^{2}$
}

\author{
${ }^{1}$ Assoc. Prof, Department of English, Madonna University Nigeria, Okija Campus, Anambra State, Nigeria. \\ ${ }^{2}$ Prof, Department of English, Madonna University Nigeria, Okija Campus, Anambra State, Nigeria.
}

\begin{abstract}
From time immemorial, the Igbo who the researchers used as a representative nation for most nations in the third world countries, has been using folk medicine. Such medicine combines faith healing, herbs and minerals. But no matter how inchoate it may sound, the truth is that it produced more elders with higher longevity than what orthodox medicine is producing nowadays. But recently, a lot of accusations are being levelled against it. To the accusers, folk medicine attacks the liver and other vital organs of the body. But then, why did it not kill our ancestors? The stand of this paper is that although some side-effects can sometimes be recorded in its usage, such is also the case in many orthodox drugs. In fact, it has been discovered that in many cases when Western medicine is quite incapable, folk medicine becomes the only solution. In order to prove that Igbo folk medicine is an indispensable aspect of health care delivery in this $21^{\text {st }}$ century, the researchers used both direct and indirect data collected from practitioners of folk and orthodox medicine, patients, elders, books and Internet sources. The discovery is that some manufacturers on seeing the shortcomings in what they are producing have resorted to adding the word herbal to their products so as to give it an air of efficacy. Even, some prominent pharmaceutical companies, Bayer being an example, have started studying and transforming folk medicine to orthodox medicine. This is because they have seen the resistance of some diseases to their drugs. Or have you heard of folk medical practitioners borrowing from orthodox medicine, making it to look like traditional medicine? When a man with bone fractures has been booked for amputation, he runs to the folk medicine practitioners for his broken bones to regain its original shape, thereby showing the superiority of folk medicine over orthodox medicine.
\end{abstract}

Keywords-Folk medicine, Orthodox medicine, Herbal products, Igbo nation, Longevity.

\section{INTRODUCTION}

Ever before the intrusion of Europeans into the Igbo terrain which in this essay is a representative nation for most countries in the third world, the indigenes were surviving on their land; their children were being born, and both the elders and the youngsters had been growing, dying, working and engaging in several activities some of which were dangerous, life threatening and annihilating. Sicknesses and wounds have been afflicting them. In spite of their precarious existence, longevity was there for those who survived initial childhood challenges which made many to lose their lives. These initial challenges had to do with some of these children suffering from sickle cell anaemia because traditional healers do not have the knowledge of cross matching the blood of intending couples. On the whole, longevity was more prevalent then than now for there are still records of elders who died when they were over 120 years of age. But today, it is celebrations galore for the few whose ages are counted to be over 80 years. Although some are of the opinion that today's short life span is as a result of economic stress, such stress was more in the olden days. Also, if orthodox medicine is capable, it can help to save more lives no matter the economic stress.

But for the Igbo people of those days to be surviving at all and for them to reach old age, they were feeding on natural foods and treating themselves with their folk medicine. Judging from today's knowledge and training on orthodox medicine, what they were using in treating themselves were nothing to write home about. To us, they were treating themselves with poison. But then, they survived to produce the present generation of orthodox or Western medicine users. Therefore, in view of the usefulness and resilience of folk medicine and in view of newly discovered influences that it has on modern medicine, it is necessary to know more about it and if possible, revive and integrate it with modern knowledge. Also, it is highly necessary to enlighten people on its 
exclusive area of coverage which modern medicine cannot handle.

Folk medicine also known as indigenous or traditional medicine is that type of medicine found among aboriginal inhabitants of a particular place. It makes use of beliefs, herbs, animal and mineral components either combined or used singly in order to bring about healing and protection to both humans and animals. According to the group, National Centre for Farmworker Health Inc of Buda, Texas (n.d.) in an online publication: "Folk medicine is the mixture of traditional healing practices and beliefs that involve herbal medicine, spirituality and manual therapies or exercises in order to diagnose, treat or prevent an ailment or illness (n.p.)." The group further cites the World Health Organization (WHO) who states that this type of medicine "is mostly practiced by indigenous or native populations and as much as $80 \%$ of the population in certain countries within Asia and Africa rely on it for primary health care" (n.p.).

On their own, Shirley Telles et al (2014, n.p.) define folk medicine in an online article thus: "Folk medicine is those traditional knowledge systems which are more often orally transmitted, have been generated by communities over centuries and use components of ecosystem which are locally available and accessible." To show the prevalence and similarities of folk medicine produced by different people, these researchers do not mince words when stating that: "There are several similarities in the folk/indigenous medicine of widely differing geographically distinct communities" (n.p.).

With this type of locally generated healing method, the Igbo people have been able to protect themselves and tackle all types of health problems that come their way. Such health problems as enumerated by Ray Tapan are: “...poisonous snake bites, neurological disorders and some others... like eye disease, skin disease, fever, allergies, headache, [birth delivery], arthritis, diabetes, diarrhoea, stomach ache and nervous disorders" (2014, p.14). This is the researcher who has so delved into the topic that he has studied the method of preparation of such medicine. According to him, these are in four categories viz: “(a) plant parts applied as a paste (b) juice extracted from the fresh plant parts (c) powder made from fresh or dried plant parts (d) some fresh plant parts and decoction" (2014, p.14). But no matter how analytical these are, the present researchers do not agree with these categories because apart from these all of which only refer to a section of the healing method, the scholar is silent on the spiritual or metaphysical aspect of folk healing which sometimes are accompanied by incantations or enchantments.
Finally on the definition of this field, Ignatius Uche Nwankwo in his work cites the World Health Organization (WHO) who in the year 2003 stated that: ...folk medicine involves health practices, approaches, knowledge and beliefs incorporating plant, animal and mineral based medicine, spiritual therapies, manual techniques and exercise applied singularly or in combination to treat, diagnose and prevent illness or maintain wellbeing (2014, p.177).

But in spite of the usefulness of this medicine and its ability in keeping the whole race before the coming of Western medicine, in spite of its superiority in handling some ailments better than Western medicine, some people are not comfortable with it. A lot of accusations are being levelled against it. This has gone to the extent that there is need not only to defend it but to enlighten those who are either confused by Western civilization or who are yet to be exposed to the achievements of our forefathers. Even to pacify and reclaim the confidence of such people, there will be a sort of integration of the two systems of healing.

\section{ACCUSATIONS AGAINST FOLK MEDICINE}

In spite of the usefulness of this type of medicine, a lot of negative criticisms and evaluations are put forth from time to time against this time-tested method of healing. These criticisms and dwarfing evaluations have gone to the extent that fearful and ignorant people are afraid of availing themselves of the potentials in this ancestral method of healing. These accusations extend from the destructive nature of this traditional method of healing to its having no generally accepted dosage and concentration, its hygienic nature, its destructive attack on the liver and the non-determination of one drug's reaction with another. But if the truth is to be told, how then was folk medicine used in the days gone by? Those whose only means of healing was this type of medicine were noted for longevity. Was folk medicine as destructive as that and longevity was recorded for those who used it as their only type of healing?

Apart from the views noted above, David Young, Ingram Grane and Swartz Ingelise (1988, n.p.) in an online publication observe that "Traditional medicine has been gradually forced underground in many societies due to pressure from missionaries and governments who perceived such practices as witchcraft." These scholars further point out another source of this problem of folk medicine. According to them, the denigration accosted to traditional healing comes from the cultural imperialism of European tradition. 
Ruth Kava (2007, n.p.) in an online article points out that the American Council on Science and Health accuses traditional healing as causing damages on the flora and fauna "because of traditional beliefs that certain things are curative." Then, the researcher quickly adds that "Yet, there is no evidence that it is so." But if collecting herbs destroys the flora and fauna, then we must stop rearing animals because they do more damages. As for the curative potential of traditional medicine, this paper will throw more light on it.

In addition, M. Wintermtz (1899, n.p.) in the online edition of Folk Medicine in Ancient India brings out a point which can also be seen to be affecting Igbo traditional healing. To this scholar, "The degraded position of the medical profession in ancient India is no doubt, due to the fact that in India as in other countries, the physician is the direct descendant of the wizard and sorcerer." In Igbo land, they are regarded as unbelievers, idol worshippers and satanic agents. This position makes it difficult for people to come near them and benefit from their wealth of knowledge.

In another online publication, Linus Chia Saalu highlights some points which also affect Igbo folk medicine. Some of these points are the unavailability of quality control of this type of medicine, lack of wellcontrolled double blind clinical and toxicological studies to prove their efficacy and safety. Then, taking some of those materials used in traditional healing, this scholar points out the dangers involved. According to him, ethanol extract of unripe fruit of Ananas cosmosus (pineapple) brings about anti spermatogenic activity; Azadirachta indica (dogon yaro or neem tree) which is used in treating malaria and chicken pox causes decrease in the sperm count; Bambusa arundinaecea (common bambo or otosi or achala in Igbo) which is used in treating stomach upset and even malaria brings about infertility in males; Carica papaya (paw paw or okwuluezi in Igbo) which is used in treating headache, painful swellings, catarrh and so on causes testicular weight decrease and testicular degenerative changes.

The scholar, Charles Daniel (2018, n.p.) in his studies dwells on folk medicine causing liver problems. In an online article, he mentions some of such local herbs that do so: Greater Celandine, Mistletoe ( $I b u$ in Igbo), etc. But in Igbo land, mistletoe is used in treating stroke, and there is no evidence that it destroys the liver.

Finally, in the array of accusations is one from Kay Sackett, R. N. Melondie Carter and Marietta Stanton. According to them, folk medicine enables individuals to indulge in self medication "or to self-treat themselves with folk or home remedies from their past, even though the medical situation may indicate a very different approach" (2014, p.113). This can be understood after considering that these remedies are easily available and any person who is not careful enough may make the mistake of applying an incorrect medicine on an ailment. But then, such can also be obtainable when considering orthodox roadside drug sellers who go by the name "Chemists." Therefore, medicine whether Western or folk as it is currently among the Igbo can be abused. Be that as it may, it is worth mentioning here that the abuse of folk medicine is less harmful to the body than some of the concoctions we call orthodox medicine or drugs.

Again, the abuse in folk medicine can be minimal since it has become part of the people. Since its existence for eons of years, it did not annihilate our ancestors. Therefore, it cannot annihilate the present generation. In all, a lot of accusations are levelled against folk medicine. Such accusations, one can see, are as a result of lack of knowledge and racial jingoism that emanated from Igbo man's contact with the Western world. Therefore, there is need to enlighten people on the merits and successes of this type of medicine. In view of this, it is the stand of this paper that folk medicine is so efficacious that it is indispensable in this era of strange diseases that defy orthodox medicine, spiritual and poisonous attacks from wicked people, weakness of Western medicine due to over use and resistance by different ailments, high cost of medical attention even in government hospitals and so on. Therefore, a lot of reasons can be garnered so as to make people understand the indispensability of folk medicine in this $21^{\text {st }}$ century.

\section{METHODOLOGY}

This research involved both direct and indirect data collection. Although some of the indirect data were gotten from people outside the Igbo nation, they are still very relevant since these people are experiencing what the Igbo nation is passing through. Such data can be accessed from books and from the Internet. For the direct data, the researchers had to meet both practitioners of orthodox and Igbo folk medicine and the ordinary people to whom the medicine is administered.

What is more, folk medicine exists in such a way that part of it is in the general medical arsenal of the people and do not require specialized knowledge. When the current researchers consulted some elders who used such knowledge copiously before the present suspicion became rife, they were furnished with a lot of general healing techniques. The other part can only be accessed through specialists in the field. These specialists are generally referred to as Dibia. These specialists are in 
different areas. When, for an illustration, dibia ngbologwuna-nkpa-akwukwo (herbalist) encounters a problem, he may consult dibia afa who is a soothsayer and can do part of the diagnosis for him. Sometimes, a person can be a specialist in the two fields.

Therefore, with these consultations, personal experiences and what was garnered from the Internet and books, the present researchers hope to put it indelibly that Igbo folk medicine in spite of its being distrusted is still very relevant and in many dicey situations can be of safer use and is more efficacious than Western medicine. Since orthodox medicine is borrowing from it so as to keep on tackling some diseases which have become resistant to it and which $a b$ initio, it cannot handle, it means that folk medicine is indispensable in handling thorny medical cases in this $21^{\text {st }}$ century.

\section{ON GENERATING HERBS AND THE EFFICACY OF IGBO FOLK MEDICINE}

Owen Davis (2010) in an online article points out that "Long before the advent of clinical pharmacy or indeed modern health care, folk medicine was linked to supernatural forces." This is because of the activities of the native doctors who dispense this type of medicine. For one, if the presiding spirit, Agwu who is in charge of the medicine does not choose somebody, the person cannot be a native healer. If he chooses somebody and the person refuses, he will afflict him with diseases and suffering. But one cannot quite say that what the people do is superstitious. That it is a sort of cult in which only the initiated participate does not make their activities superstitious. Judging from their successes, there is something behind what they do; let it be noted that "it is becoming increasing clear that not everything can, at the moment, be explained by means of empirical observation alone" (Nwala, p. 105).

On interviewing some of these practitioners, some said that for them to know the curative ability of leaves, stems, roots, grasses, etc, their Agwu would direct them. Others said that these plants would talk to them whenever they were in the forest looking for a cure for any disease. A story the researchers got from Awuda Nnobi in Idemili South Local [L] Government [G] Area [A] of Anambra State revealed how one Late Mary Samson Metu was suffering from a certain stomach ailment. In a dream, she was shown a certain palm tree at the foot of which were some herbs. She was told how to use the herbs. When she woke up, she did as she saw in the dream and with that she was healed. Then, she started using the same method to heal others.
This method of acquiring healing knowledge among the Igbo is not different from what was recorded in India. As it is in India, the healers who are known as Ojha: ... have deep connection with healing culture. They are known as the god-gifted individuals of our folk society who may heal snake bites as well as common diseases in different ways like touch/stroke method. Naturally, they use ritualistic approach. They have a great power to use a variety of therapies to heal snake bite infection (Tapan, 2014, p.14).

However, Igbo medicine practitioners have been noted for achieving some feats which orthodox medicine has never dreamt of. As an illustration, there was a pastor one of the researchers met in Onitsha who narrated how his stomach ulcer problem went to the extent that the doctor recommended carrying out surgical operation on him. But with two thousand naira only ( $\$ 2000.00)$, a traditional healer set him free. At Uli in Ihiala L. G. A. of Anambra State, the researchers saw cases of those who were healed of diabetes. To the best of their knowledge, Western medicine cannot achieve this feat. Medical doctors only control it for the problem to become manageable.

Also, there are cases of very sick people suffering from poisoning who orthodox medicine diagnosed of suffering from nothing. Yet, by merely looking at them, they were dying. One of such people the researchers met at Uwani Enugu told the researchers of how he went to EdeOballa in Nsukka and was healed at a very low cost. He brought out the photograph of what he vomited out. The thing looked like a cockroach except that the head had four sides. According to the young man, since he vomited that thing out, what was crawling in his chest has stopped. Asked whether he was not tricked since something like that which was alive could hardly live inside a person's chest, he said no. According to him, there were others who came along with him and who were told that they were not suffering from poison. If the healer was a trickster, he would not have told those people to go because they were not suffering from poison. When one of the present researchers suggested that his healing could be as result of placebo effect, the man said that all he knew was that he has been healed. According to him, placebo effect is obtainable even in Western medicine.

However, the problem with these traditional healers is that they hardly release the most important formulas of their medicine. They do so only to their favourite children some of whom may be apathetic to their parents' leaning. In this way, the Igbo nation has lost much medical knowledge acquired in the days gone by. All the 
same, the reason given above does not in any way make folk medicine less effective in the treatment of diseases.

For illustrative purposes, the late Igwe Ezeokoli 1 of Nnobi in Idemili South L. G. A. of Anambra State was noted for operating surgically as the need arose on his patients. In the course of this research, it was discovered that none in his family knows anything about that method of healing. That is also obtainable in the family of one of the best bone setters that was ever born in the land, Ofodumogu in Adazi-Ani in Anaocha L. G. A. of Anambra State. He was so professional that fractures and many desperate cases in many teaching hospitals and orthopaedic centres were brought to him and by knocking together two bones and using other medications, what would have ended up as amputations were treated by him. Our informant Ebele Afulukwe of Umuoji in Idemili South L. G. A. narrated how one man who was awaiting amputation at National Orthopaedic Hospital, Enugu was whispered to and directed to Ofodumogu. Today, the man is walking about without limping but the old healer is no more.

What these people use for their healings are natural and simple materials that are easily available as can be illustrated from the list below as the researchers got them from a practitioner, Nwamuoma of Eziehulu, Awuda Nnobi in Idemili L. G. A. of Anambra State:

i. Mixture of lizard's faeces, palm oil and salt makes boils to form pus so that it can be lacerated.

ii. Put four leaves of bitter leaves into your mouth if you are suffering from cough. By chewing them slowly and allowing the bitter saliva to be draining down your throat, the cough will soon disappear, and even when it is a dry cough, you will sleep soundly at night without coughing from time to time. Bitter cola is also very efficacious in treating fresh cough.

iii. When somebody is suffering from toothache no matter the seriousness of it, let the person cut out many pieces of the bark of a coconut tree. Boil the pieces with water until the water turns brownish in colour. As warm/hot as the person can endure, let him pour the brownish water into his mouth, wobbling it up and down until it becomes cold. Let the person do so as many times as he can endure at a stretch three times a day. Before one week elapses, the toothache must have been healed even when the tooth has a hole. The researchers hereby appeal to you not to go for tooth extraction for this method is highly efficacious.

iv. The water of neem leaves (Dogonyaro), paw-paw leaves and lemon grass leaves cures malaria.

v. Grind balls of red potato into a paste; mix it with water and drink the mixture three times a day or be chewing cabbage the same number of times. The two can curtail stomach ulcer.

After looking at the above, one wonders, what is so dangerous in them that people's livers and kidneys will be damaged. Some of the medications for oral consumption make up part of the food ingredients of the people. There may sometimes come up some problems but then, the problems may not be as serious as it is said or generally thought of. Such problems also can be obtained in modern medicine. Therefore, if modern or orthodox medicine is not vilified because of this, then why the bias against traditional medicine? This view is not far from that of Sackett, Cartor and Stantor (2014, n.p.) as it is in their online publication:

It is clear that herbs have much in common with prescription medication, including possible powerful effects on the body and the potential for side effects and interactions. Herbs may be safe and effective for home use, but they should be used in the proper forms with the advice of qualified health care professionals who can offer appropriate guidance.

Also, because of the availability of these materials, traditional healing can be obtained at a very low cost. What is more, the belief is that when the healer's charge is high, the spirit in charge of healing known as Agwu, will neutralize the medicine making it ineffective. Thus, people are helped no matter how poor they are. This observation is similar to what was observed in India:

Lots of people can be saved from the side effects of imported medicines. Poor people can be released from huge economic pressure because imported medicines are very expensive. It is then understood why Prime Ministers Jawaharlal Nehru and Indira Ghandi advocated the integration of the best of indigenous medicine with modern medicine (Tapan, 2014, p.16).

That is the call in India. It should also apply in Nigeria but not so in China where David Young, Ingram Grane and Swartz Ingelise (1988, n.p.) observe in an online publication that: "... the government itself has promoted a dual system in which paramedical personnel 
... are trained in both traditional and modern orthodox diagnostic and treatment procedures."

The idea that traditional medicine is cheap can also be found in the online publication of Peter McGuire (2016, n.p.). Just as it is in Igbo culture where Agwu stipulates the cost of healing or else he makes the medicine ineffective, so it is in Ireland where "The attitude was that you never paid healers. They had a gift, and helping out the neighbours was a decent thing to do." The scholar goes on to recall that "One healer had a cure for farsy and decided to start charging money but he couldn't cure from that day on."

Also, emphasized in traditional medicine is the cordial relationship between the healer and the patient. One woman, Grace Okeke of Nnobi was told by a healer that he would not have the chance to go to the village with her in order to get the leaves of a particular plant which was near his compound wall. He directed her on how to get the leaves and how to use them. She did as she was directed but the expected reaction on her body could not manifest. Then, the mother-in-law of the woman told her that the leaves did not work because the healer's hand did not touch them. She was later proved right, for when the man went personally, plucked the leaves and gave them to her, the expected reaction of the leaves was experienced by the woman. To the Igbo people, "Healing is in the hands of the doctor."

Next, there is a type of healing method which has nothing to do with oral consumption. From modern perception, this can be said to be faith healing. The traditionalists see it as the work of the healer god, Agwu. In other words, a supernatural is working behind the scene. Normally, such medicine goes along with incantations because the native believes in the efficacy of the spoken words. Because nothing is ingested, there is nothing like side effects as well as negative effect on the liver and kidney and all the other accusations against traditional medicine. For illustrative purposes, here are again five traditional healing methods that have nothing to do with taking anything orally.

i. If the breasts of a girl have grown bigger than the expected size, gently knock the head of a broom or partly burnt but extinguished firewood on the breasts three times a day. In less than a week, the breasts will reduce to its normal size.

ii. When suffering from sour throat, find a crack in a wall and whisper into it. Promise it what you will do for it if it heals you.

iii. Conjunctivitis (oku anya) is highly infectious. For one to be free, let one fetch firewood even if it is just a broken broom stick for the sufferer.

iv. If you have a knife or machete cut and you want speedy healing of the wound, put the knife or machete into a stem of plantain or banana.

v. Ona abuke which is a type of Diescorea dumetorum (bitter yam) is poisonous when eaten the same day it is cooked. You have to leave it overnight. For the treatment of the poison that results from eating it, carry the sick person from one side of the compound wall to the other.

The question that first comes to the mind of the readers of this second list is: "Can these work?" Yes, they do. One of the researchers witnessed when the first one was applied on the breasts of a 10-year old girl whose breasts were so bulging that they were as big as those of a 20-year old girl. It was just by chance that a visitor who came to see the mother told the girl to use a broom on "those things." The researcher got interested and she explained that with pelting the breasts with the bottom of a bunch of broom that they would shrink to normal size. This was witnessed in less than a week.

In addition, one of the present researchers also witnessed when a man who was behaving as a drunkard because he cooked and immediately consumed ona abuke was hoisted over a wall by a group of men. One group on one side of the wall carried him over the wall for another group at the other side to receive him and place him on the ground. As soon as the second group laid him on the ground, he recovered, with his senses back to normalcy.

While discussing the first episode with an orthodox medical practitioner I. E. Anigbogu from Oba in Idemili South L. G. A., he said that such method can be curative. According to him, this is the case of mind over matter which belongs to the field of psychotherapy. But he lamented that many traditional healers over indulge on psychotherapy. That such a method of healing is workable is also supported by Mary Oladunmi Adeware. According to this scholar, "Studies regularly point to placebo effects (both positive and negative) which are entirely caused by the power of expectation or preconceptions" (2012, p.45).

On interviewing Anigbogu further, he revealed that his grandfather was a native healer and as such, he was in a position to assess the efficacy of both folk medicine and orthodox medicine. He himself in 1956 had a complex fracture on his leg. When he was taken to lyienu Hospital at Ogidi, the doctors wanted to amputate his leg. His grandmother refused saying that there had never been somebody who was one-legged in the history of the 
family. She then took him to a native bone setter, Ofiabuluaku of Ojoto in Idemili South L. G. A. of Anambra State. Today, nobody who sees the erudite lawyer and western-trained medical doctor Anigbogu, can ever know that he went through such an experience.

Anigbogu went on to reveal that there are many workable herbs but some of them have side effects. He then narrated the case of a small girl who died while he was treating her of measles. By then, he was a housemaster. What happened was that the parents who were from Delta State believed that by making noises that the spirit of measles would run away and leave the girl alone. By the time she was brought to his hospital, her condition was critical and so the girl could not survive. In other words, the second enumerated cases above do not always work. He further explained that some of the cases in the first list are workable with some being based on sound scientific knowledge but rendered from the native perspective.

On being asked how he saw the idea of some native healers saying that either they obtained their medicine through dreams or that the plants themselves call out their healing power, Anigbogu opined that whether we believe it or not, there is an external power who we may call God or any other name. He further said that such powers do influence human lives and actions. What was more, it is not only in folk medicine that dreams influence the outcome of expected results. It also happens in the sciences.

Illustrating his statement that it happens in the sciences, he gave the example of August Kekule when he was experimenting on the benzene structure. Further research on that area revealed to the present researchers that the chemist in 1890 at the $25^{\text {th }}$ anniversary of the benzene structure discovery narrated of two dreams that he had at the key moments of his work. According to Michael Verderese in an online publication, Kekule's dream revealed how:

... atoms danced around, then formed themselves into strings, moving about in a snake-like fashion. This vision continued ... [showing moving atoms in a] snake-like fashion. . . until the snake of atoms formed itself into an image of a snake eating its own tail. This dream gave Kekule the idea of the cyclic structure of benzene.

Since Kekule solved a thorny scientific problem with what he got from dreams, it means that major problems can be solved using metaphysical means. Therefore, those who obtain their folk medicine either through Agwu, the god of healing who speaks through the herbs or those who get their healing herbs through dreams are on the right track. Since what they came up with comes from sources greater than humans, the assumption is that their medicine must be more efficacious than medicines that come out only through human ability. But this enquiry must consider how to sustain the health of both present and future generations.

\section{EFFICACY AND FUTURE OF FOLK MEDICINE}

Is it safe to be taking folk medicine in this present generation? Yes, it is in spite of some side effects it is accused of. This is because even orthodox medicine has its dangerous side effects. Furthermore, there are many areas where folk medicine is far more efficacious or superior to orthodox medicine. As an illustration, in the course of this research as we cited above, we met one man, Stephen Ogbonna who was living in Uwani, Enugu. He has been bedridden for over one year. Before then, he had wasted a lot of money in different hospitals but without being healed. Finally, somebody directed him to Ede-Oballa in Nsukka Area of Enugu State. There, a healer diagnosed his problem as coming from poison. He gave him some emetic drugs after which he vomited something that looked like a cockroach but had a head that had four sides. The thing was alive. After, he noticed that what had been moving about in his chest has been evacuated and his health started improving.

Take it or leave it, Western medicine has not been known to cure or control poison cases. But how frequent are such cases? Very frequent indeed! Evil minded people tend to be more diabolic with increase in hardship and with stringent economic measures. Since hardship in this nation is in the increase, it is projected that evil minded people will be in the increase. Also, they are more devilish minded when others are progressing. Therefore, there is no certainty that some will not progress more than them. That will draw their ire and the invention of more dangerous poisons. That can explain the existence in Igbo society such poisons like: Enyi-ure, Ukwara ntilili, Acha ele, Mmiwu and so on. These are areas where orthodox medicine can do nothing. The worst part of the whole thing is that in some cases, when tested in laboratories, the patients are found to be suffering from nothing.

The above observation is not just peculiar to the Igbo people or Nigerians. In the Republic of Turkey as observed in the online article "Folk Medicine" (n.d.):

... some people do not trust modern medicine in cases like the evil eye or when someone is under the influence of an evil spirit. Both folk and modern medicines are used in some disease like asthma or to deal with heart problems. Cancer and 
other diseases which require surgery are totally left to modern medicine.

Further on the efficacy and exclusive areas of folk medicine, it was discovered that the first traditional ruler of Nnobi, Igwe Ezeokoli 1 used to carry out surgical operations on his patients. He was not the only person who could do so. During the interview with the folk medicine practitioner Nwamuomma, he narrated to the researchers about some traditional healers who used local methods to carry out surgical operations on their patients.

In extension, which orthodox medicine can be used to treat demonic oppression, possession or obsession? Scientific records as shown above prove that discoveries can be gotten from metaphysical sources. Do we take it that only good ends can come from such realms? If something good can come from there, something bad can also emanate from such a realm. When it does so, can we use orthodox medicine to tackle the problem? The answer is left for you.

However, Ignatius Uche Nwankwo has the answer which can serve as a defence of folk medicine. According to the scholar:

The understanding that certain diseases are sequel to [the] anger of the gods or are due to demonic attacks by enemies and evil forces alike provide further attractions to folk medicine even in this age. Traditional healers are seen as [being] capable of communicating with the spirit world, offer acceptable sacrifices to appease offended spirits and/or cast out demons (2014, p.183).

At the present age, folk medicine shows its originality and potency through some modern medicine. Because its potency is no longer in doubt, some pharmacists study them as they take them into their laboratories. The result is that some of the drugs dispensed in orthodox hospitals are transformed folk medicine. That explains why it is recorded in the online encyclopaedia, Wikipedia (n.d.) that "some modern medicine is based on plant phytochemicals that had been used in folk medicine." To be specific, in the online site of the Ministry of Culture and Tourism of Turkey, it is clearly stated that: "... aspirin used as painkiller appeared as a development of quinine and cocaine which had been used by folk medicine for a long time. In the same way, research has proved that some herbs used in folk medicine were really effective in curing diseases."

There is no iota of doubt that traditional medicine is superior to the orthodox one. That can explain why researches are on-going to see how to standardize and popularize this original medicine. It is in the process of this new wave of study that a Nobel Prize Winner for
Medicine, Tu Youyou discovered: “... a breakthrough drug after poring over 2,000 ancient herbal recipes. Dr. Tu Youyou's discovery, the anti-malarial Artemisinin, derived from wormwood, is credited with saving millions of lives." It is when one sees lapses in what one has, that there arises the need to look elsewhere. That which produces the needed result must be superior. Therefore, folk medicine in many respects is superior to orthodox medicine.

For Chris Pit (2015) to prove this point further in the online edition of BBC News, he points out that: "From opium in poppies, to quinine derived from the cinchona tree, to digoxin from foxgloves, there are many gems unearthed from the past -- that have true testable medical benefits." He then lists five herbs and their medical usefulness. According to him, these are: white sap from milkweed (Euphorbia peplus) which is used in treating warts; leeches for bloodletting which is used for tackling many diseases; bark of the willow tree for pain relief, etc. According to him, the mega pharmaceutical company, Bayer since 1915 has been selling the last named as aspirin. Even, recent discoveries have shown that it reduces the risk of strokes, prevent cancer, etc.

In order to show the gems and nuggets in folk medicine, Pit in the same online article shows that "... there is now a whole branch of science dedicated to the study of traditional medicine, ethnopharmacology (n.p.)". To show that Pit is not the only person who knows this fact, Davis Owen (2010, n.p.) in The Pharmaceutical Journal which is another online publication shows the influence of folk medicine by attracting numerous fields of study to look into it. According to this researcher: “... a range of relatively new disciplines, namely medical anthropology, ethnobotany, phytotheraphy and ethnopharmacology, have provided an impetus for looking again at the nature and value of Europe's old medical traditions."

If folk medicine is just an empty something, none would have been motivated to look into it. If there is no lack in the existing orthodox medicine, then there will be no need to look elsewhere. But then, in spite of the plethora of negative criticisms levelled against folk medicine, the fact still remains, according to Linus Chia Saalu (n.d.) in an online publication, that the: “...inability of Western medicine to provide cure for some diseases and infections (e.g. HIV and AIDS) makes it necessary to look elsewhere." That place that should be looked into is folk medicine which has, in spite of negatively, incorrectly and hastily produced assessments is said to be everything bad and backward but actually has been observed to have "... little or no side effects; with [the] use of herbal medicines are other factors, often stated in favour of herbalism." 
Also in favour of herbal medicine is its easy accessibility. If somebody is working in the farm and gets wounded, there is no need going outside to get treated. Let the person look around for the herb obachili-be-onyenwuru-anwu. The leaves of this plant when squeezed, produces green liquid which can be smeared on the wound. Though it can be painful, it will not only shield the person from bacterial infection, the wound will heal quickly. This is not the forum to talk about its other medicinal qualities. Again, at home when somebody receives burns or is wounded, going to the hospital may be both time and money consuming when Alovera plant is handy for the plant can conveniently bring about healing of burns and wounds.

In assessing the advantage of folk medicine over orthodox medicine, we must note the cost of health delivery in the hospital. What is more, because of the few medical doctors compared with the large population they are to attend to, the cost of hospital bill is in the high side. When compared with the effect of poor economy on the struggling populace, one can see that there is need to popularize and standardize folk medicine. Let quacks be sent packing and let the good aspects be brought to the fore. As Saalu states in the online paper earlier cited:

$\ldots$ it is estimated [by the World Health Organization] that in sub-Saharan Africa, there is one traditional healer for every 500 people whereas there is only one medical doctor for every 40,000 people. Therefore, the importance of herbal medicines in the life of Africans cannot be overemphasized.

In view of the lapses in orthodox medicine, a lot of new products are coming up. For manufacturers to sell their products, they have to attach the word herbal to them since many people have seen that the "chalk" (or so Igbo people sneeringly and in denigration refer to orthodox tablets) cannot be of much use. That situation explains why today there are: herbal toothpaste, herbal tea, herbal soap, herbal medicine and a host of other herbal preparations. When people buy them, they do so thinking that they are buying something from a natural source and these must be highly efficacious.

That some manufacturers append the word "herbal" to their products so as to attract buyers, points to the fact that there are lapses in what they are selling, and for them to sell their products, they have to add what can attract customers. These customers have seen the limitations in the potency of Western medicine where fractured limbs end up being amputated; ordinary malaria refuses to be cured, or reoccurs after a short while; diabetes can only be managed and cannot be cured; decaying teeth are extracted and not cured, etc.

Situations such as this can explain the observation

of Linus Chia Saalu (n.p.) in an online publication:

In the past two decades, there has been a global resurgence of interest in traditional medicine for the treatment of ailments that defy orthodox medicine principally because many diseases have defied or developed resistance to conventional drugs as well as a health system closer to the rural poor.

It is not only in Igbo land that this situation is obtainable. In short, even in civilized nations, this is what is happening. As it was observed in America: "Herbal and nutritional supplements used in the United States are increasing, including use among older adults. Often, older adults do not inform their care providers that they are using dietary supplements" (Sackett, Carter and Stanton, 2014, p.116).

But then, there is need for the government to look keenly into folk medicine if not for anything but to evict quacks who muddle the water and bring bad name to the healing process which for unnumbered centuries has been shielding the people. Also to be considered are: standardization of products, discerning the active ingredients in each drug, double blind toxicological studies that can help in determining the efficacy and safety of each drug, side effects, drug interaction with others, etc. With the determination of all this, it can be possible to see how to integrate the two types of medicine.

\section{CONCLUSION}

From time immemorial, Igbo people have been making use of folk medicine. This type of medicine is holistic in its approach in that it handles problems from three perspectives -- physical, emotional and spiritual. It has been found to be so powerful that some ailments that defy orthodox medicine can be conveniently taken care of. Where orthodox medicine comes up with such irreparable results like amputations, people who are adepts in folk medicine repair the damage so well that nobody can ever guess that there was any problem before.

However, due to the presence of quacks, lack of documented studies in the field and other human errors, a lot of accusations are levelled against it. Some of such accusations can be in its side effects, lack of dosage, etc. The result is that these accusations are scaring people away, thereby debarring them from benefiting from the healing prowess obtainable in this type of medicine.

However, this does not scare everybody away. That can explain its resurgence among many people from 
such places like America, China and India. In fact, in India, the call has come from the government that folk medicine be merged with orthodox medicine. Such can augur well for better health care delivery. Even in America, some elderly people without informing their personal doctors visit folk medicine practitioners. To show the usefulness of this type of medicine, some manufacturers append the word "herbal" to their products since they have seen that people have become enamoured with the potency and naturalness of herbs.

Finally, since many diseases are becoming resistant to orthodox medicine, scientists are turning to folk medicine, studying its drugs and adapting them to look modern. Therefore, folk medicine remains the only saving grace that can save humanity from extinction. What is more, when medical doctors are too few to attend to the enormous population that needs them, since their medicine and health delivery are out of the reach of the common man, the only solution can be found in folk medicine.

\section{REFERENCES}

[1] Adewara, Mary Oladunmi. (2012). Scientific explanations and educational implications of superstitious beliefs held by Ijara-isin people of Kwara state, Nigeria. An unpublished master of education project, submitted to the Department of Science Education, Faculty of Education, University of Ilorin, Ilorin Nigeria.

[2] Daniel, Charles. (2018). Herbal medicine and liver damage. [online] Available: https://www.verywellhealth.com.

[3] Davis, Owen. (2010). Fairies, witchcraft and healing charms: How folk medicine and the supernatural entwined. The pharmaceutical journal. [online] Available: https://www.pharmaceutica-journal.com.

[4] Kava, Ruth. (2017). Folk medicine hurts more than humans. [online] Available: https://www.acshiorg .

[5] McGuire, Peter. (2016). Herbal medicine: A relic of the past or a sign post of the future. The Irish times, [online] Available: https://www.Irishtimes.com.

[6] National Center for Farmworker Health Inc. Folk medicine and traditional healing. [online] Available: www.ncfh.org.

[7] Nwala, T. Uzodimma. (1985). Igbo philosophy. Lagos: Lantern Books.

[8] Nwankwo, Ignatius Uche. (2014). Resilience of folk medicine among the Igbos of southeast Nigeria. European scientific journal. 177-187.

[9] Pitt, Chris. (2015). Five old remedies that are still healing us today. BBC News. [online] Available: https://www.bbc.com.

[10] Republic of Turkey Ministry of Culture and Tourism. Folk medicine. [online] Available: www.kultur.

[11] Saalu, Linus Chia. (n.d.). Nigerian folklore medicinal plants with potential antifertility activity in males: A scientific appraisal. Research journal of medicinal plants. Vol. 10, No. 3. 201-227.
[12] Sackett, Kay, R. N. Melondie Cartor and Marietta Stanton. (2014). Elders' use of folk medicine and complementary and alternative therapies: An integrative review with implications for case managers? Professional case management. Vol. 19, No 3, 113 - 123.

[13] Tapan, Ray. (2014). Role of folk medicine in primary health care: A case study of west Bengal and India. International journal of interdisciplinary and multidisciplinary studies. Vol.1, No. 2, 13-18.

[14] Telles, Shirley et al. (2014). Research on traditional medicine: What has been done, the difficulties and possible solutions. [online] Available: https://www.hindawi.com.

[15] Wikipedia Free Encyclopedia. Traditional medicine. [online]

Available: https://en.wikipedia.org/wiki/traditionalmedicin e.

[16] Winternitz, M. (1899). Folk medicine in ancient India. Vol. 58, No. 1497. [online] Available: https://www.nature.com.

[17] Young, David, Ingram Grane and Swartz Ingelise. (1988). The persistence of traditional medicine in the modern world. Cultural survival quarterly magazine. [online] Available: https://www.culturalsurvivalporg. 